NBER WORKING PAPER SERIES

\title{
THE COMPOSITE INDEX OF LEADING ECONOMIC INDICATORS: HOW TO MAKE IT MORE TIMELY
}

\author{
Robert H. McGuckin \\ Ataman Ozyildirim \\ Victor Zarnowitz \\ Working Paper 8430 \\ http://www.nber.org/papers/w8430 \\ NATIONAL BUREAU OF ECONOMIC RESEARCH \\ 1050 Massachusetts Avenue \\ Cambridge, MA 02138 \\ August 2001
}

We would like to thank Phoebus Dhrymes, Chris Sims, members of the Conference Board Business Cycle Indicators Advisory Panel, and seminar participants at the CIRET Conference for helpful comments and suggestions. All remaining errors are of course ours. The views expressed herein are those of the authors and not necessarily those of the National Bureau of Economic Research or The Conference Board.

(C) 2001 by Robert H. McGuckin, Ataman Ozyildirim and Victor Zarnowitz. All rights reserved. Short sections of text, not to exceed two paragraphs, may be quoted without explicit permission provided that full credit, including $(\mathbb{C}$ notice, is given to the source. 
The Composite Index of Leading Economic Indicators:

How to Make It More Timely

Robert H. McGuckin, Ataman Ozyildirim and Victor Zarnowitz

NBER Working Paper No. 8430

August 2001

\begin{abstract}
$\underline{\text { ABSTRACT }}$
A major shortcoming of the U.S. leading index is that it does not use the most recent information for stock prices and yield spreads. The index methodology ignores these data in favor of a time-consistent set of components (i.e., all of the components must refer to the previous month). An alternative is to bring the series with publication lags up-to-date with forecasts and create an index with a complete set of most recent components. This study uses tests of ex-ante predictive ability of the U.S. leading index to evaluate the gains to this new "hot box" procedure of statistical imputation. We find that, across a variety of simple forecasting models, the new approach offers substantial improvements.
\end{abstract}

Robert H. McGuckin

The Conference Board (212) 339-0303

robert.mcguckin@conference-board.org

Victor Zarnowitz

The Conference Board and NBER

(212) 339-0432

victor.zarnowitz@conference-board.org
Ataman Ozyildirim

The Conference Board (212) 339-0399

a.ozyildirim@conference-board.org 


\section{The Composite Index of Leading Economic Indicators: How to Make It More Timely}

\section{Introduction: The Problem and Attempted Solutions}

The current procedure for calculating the composite index of leading indicators does not use the most up-to-date information. The composite index methodology ignores currently available data on stock prices, bond prices, and yield spreads in favor of a time-consistent set, i.e., data for a past month for which all or at least most components of the index are available. This is a major shortcoming. For the United States, for example, the index of leading indicators published in March uses data from January despite the availability of February values for at least two of the components, namely interest rate spread and stock prices. ${ }^{1} \quad$ The problems are more acute in most foreign countries where many indicator series are available with lags of more than one month, sometimes as long as 3-5 months.

Faced with lags in the availability of many series, the practice has been to calculate the index with a partial set of components in most foreign countries and occasionally in the U.S. Typically, at least half of the components of an index are required before this procedure is used. For example, according to the rules used by the OECD, the minimum percentage of component series required before a 
composite index can be calculated lies between 40 and 60 percent depending on the country (see OECD web page http://www.oecd.org/std/li1.htm).

While such rules create a more up-to-date index, they raise many serious problems. The effective weights used to calculate the contributions of the components, for example, often change dramatically without a consistent set of components. Thus, there is a trade-off between the coverage and the timeliness of the leading index. The more complete its coverage, the less timely is the index.

The method we propose uses current financial information along with estimates of the values of variables that measure the "real" state of the economy but are only available with a lag. It offers an alternative to replace arbitrary rules such as the 50 percent rule discussed above. The proposed index covers a complete set of components, some of which are based on actual data and some on forecasts. ${ }^{2}$ The problem we face here is how to derive and test the short-run predictions of those components of the index that are missing for the current publication period.

In order to evaluate the new methodology, we construct alternative indexes that bridge the lags in the arrival of the component data by means of extrapolations or forecasts and compare them with a benchmark "ideal" or

\footnotetext{
${ }^{1}$ Data for nominal money supply, M2, are also available, but the consumer price deflator used to produce the real money supply indicator is not.

${ }^{2}$ The historical series for the index would be revised each month as the data unavailable at the time of publication become available. Such revisions would be treated as part of the monthly data revisions, now a regular part of indicator programs.
} 
complete index which by construction has no data lags. However, the benchmark index cannot be constructed, except ex-post, i.e. historically.

The forecasts that are included in the alternative indexes are out-of-sample forecasts based on a rolling sample of presently available (i.e., post-revision) data. Each forecast uses only the data up to the corresponding publication date. Hence, we are dealing here with a set of comparative analyses in pseudo real time. In order to address issues arising from data revisions, we repeat the tests using realtime analysis with the pre-revision U.S. data that have actually been used at the time of publication. This work shows that the pseudo real-time results are close to those using real-time data. However, it is only for a limited period, namely 1989-2000, that the unrevised vintages of data have been preserved in original form first by the Bureau of Economic Analysis in the U.S. Department of Commerce, and later The Conference Board.

Based on these results, it would appear that the pseudo real-time analysis can be applied to foreign country leading indexes, where the available data do not allow for true real-time evaluations. Analyses of the indexes for UK and Germany, which were performed across a wide choice of forecasting models, suggest that there are real gains from adopting the new procedure in foreign country leading indexes as well. However, more work is needed on the foreign indexes, and a complete parallel analysis of how the new methodology works for them is reserved for a separate paper. 
The next section outlines the composite index methodology: the current procedure, the proposed alternative, and the choice of the forecasts for the missing components of the leading index. Section three introduces the benchmark index and compares its historical performance with the records for the current and the alternative indexes. We show that the current procedure is inferior to the benchmark ("ideal") index, and present evidence that the alternative index approximates the benchmark better than the current index. Section four shows how three leading indexes compare in predicting changes in the economy represented by the U.S. coincident index. Again, the new procedure outperforms the current one. The last section contains our concluding comments.

\section{Composite Index Methodology}

\subsection{Current Procedure}

In constructing the leading index, the present approach is to use data with the shortest lags required for all of the index components to refer to the same past month. Let $X_{t}$ be the vector of the indicator series that are available in "real time," i.e., in the current publication period, t. Variables in $X_{t}$ are generally financial indicators such as stock prices, bond prices, interest rates, and yield spreads. Let $Y_{t}$ be the vector of the indicator series that are available only with lags, i.e., those variables that are not available in the current publication period. Variables in $\mathrm{Y}_{t}$ are generally data on various aspects of real macroeconomic 
activity and price indexes. In the U.S., these variables as a rule lag behind $X_{t}$ by one month (i.e., the reported data refer to $\mathrm{Y}_{t-1}$ ).

Let $I(\cdot)$ denote the indexing procedure used to transform the data into the index number for each month. ${ }^{3}$ Then, $I_{t}=I(\cdot)$ denotes the value of the index in the publication month, $t$. Thus, under the current procedure the most recent value of the index for month $t$ is $I_{t}^{C}=I\left(X_{t-1}, Y_{t-1}\right)$; its previous value is $I_{t-1}^{C}\left(X_{t-2}, Y_{t-2}\right)$, and so on. Although available, the $X_{t}$ values are not used in the publication month, which amounts to throwing away the most up-to-date information.

Where the effective publication lags of the relevant data do not exceed one month in length, as is the case in the U.S., the current index is essentially a oncelagged version of the best-timed index. Indeed, assuming complete information in month (t-1), $I_{t}^{C}$ can be represented as $I_{t-1}$, where $I_{t}$ is the actual value of the Leading Index at $\mathrm{t}$ when all the data are available for $X_{t}$ and $\mathrm{Y}_{t}$ (this is the "best" state of the index given its full set of selected components; see part 3 below on the definition and uses of the benchmark index.) However, this abstracts from any intervening data revisions, which in actuality may be, and often are, quite significant.

\subsection{The Proposed Alternative}

\footnotetext{
${ }^{3}$ On details of indexing, see The Conference Board, Business Cycle Indicators Handbook, forthcoming 2001.
} 
The main idea behind the more timely Leading Index we are proposing is that it incorporate most recent available values for the $\mathrm{X}$ variables and good, costeffective estimates of the Y variables for the matching period. Thus, instead of the current index, which in the best (U.S.) case can be written as $I_{t}^{C}=I\left(X_{t-1}, Y_{t-1}\right)$, we have an alternative index $\hat{I}_{t}^{A}=I\left(X_{t}, \hat{Y}_{t}\right)$, for all $\mathrm{t}=1 \ldots \mathrm{T}$. Here the symbol ${ }^{\wedge}$ refers to a magnitude based at least in part on some kind of forecasting and $\mathrm{t}$ refers to the latest complete month at the time the value of the index is released (e.g., February for the index published in the beginning of March). ${ }^{4}$

The leading indicators tend to move ahead of coincident indicators. For example, businesses adjust hours before changing employment by hiring or firing, or they place new orders for machinery and equipment before completing investment plans, etc. Thus the composite index of leading indicators can help predict changes in the composite index of coincident indicators, which reflect the present state of the economy. The current leading index, $I_{t}^{C}$, performs this function with errors that are due largely to missing data and other measurement

\footnotetext{
${ }^{4}$ The $\hat{Y}_{t}$ forecasts for the U.S. will be restricted to one month ahead, but for other countries multi-step forecasts of $\hat{Y}_{t}$ are likely to be necessary.
} 
problems. In the proposed index, $\hat{I}_{t}$, the main source of errors is presumably the deficient forecasts of $\hat{Y}_{t}$.

If the errors of $\hat{I}_{t}^{A}$ are on balance over time smaller than those of $I_{t}^{C}$, the new procedure is to be preferred. Conceivably, it is possible that $\hat{I}_{t} A$ is inferior to $I_{t}^{C}$. However, using $X_{t}$ instead of $X_{t-i}$ should give $\hat{I}_{t}$ considerable advantage. Other reasons for expecting the procedure to be an improvement are: (1) the errors of the $\hat{Y}_{t}$ forecast should be limited, since they typically will be for short intervals (one or a few months), (2) the individual errors of the components of the vector $\hat{Y}_{t}$ may offset each other when combined to form the composite index.

\subsection{The Choice of Forecast}

There are various ways to forecast $Y_{t}$. Here, we focus on autoregressive models, estimating the values of the components in $Y_{t}$ for the publication month with an i-th order autoregressive model. Thus, the alternative index is $\hat{I}_{t}^{i}=I\left(X_{t}\right.$, $\hat{Y}_{t}$ ) for $i=1,2,3, \ldots$. An example is $\hat{I}_{t}$ where only the once-lagged values of the series with publication lags are used to forecast their missing values. In our tests, 
we examine the AR(i) models with lag lengths, i, varying from one to four. ${ }^{5}$ As will be shown below, this approach tends to give results that improve strongly for $i=1,2$ and only mildly for $i=3,4$, and are generally acceptable.

A simple alternative to the AR (1) and AR (2) forecast models is to use the most recent values of all currently available data regardless of the period. This amounts to forecasting the missing data using an autoregressive process of order one where the constant is constrained to be zero and the coefficient is constrained to be one (i.e. $\left.\hat{Y}_{t}=Y_{t-1}\right)$. Then this "mixed-periods" index is $\hat{I}_{t}=I\left(X_{t}, Y_{t-1}\right)$. This approach also avoids the problem of discarding up-to-date information and is easy to implement; it improves on the current index but the results of the unconstrained autoregressive processes are better, hence preferred.

We also rejected adding the available data in $X_{t}$ to help forecast $Y_{t}$ (that is, using lagged values of $X_{t}$ as well as lagged $Y_{t}$ to forecast $Y_{t .}$ ). This procedure, even though it could provide somewhat better forecasts, raises important complications in the construction of the leading index. This is so because the series in $X_{t}$ are components of the composite index, and using the values of $X_{t}$ in both the index and the forecast could distort the weighting scheme in favor of the financial variables.

\footnotetext{
${ }^{5}$ Ideally, the number of lags, i, should be chosen optimally on a case by case basis. For practical reasons associated with production of the indexes on a monthly basis, it is advisable to use the same forecast model for fixed periods of a year or two. Therefore, we focus on relatively simple lag structures that can be easily implemented and these are fixed for the entire sample period.
} 


\section{The Benchmark Index and Its Uses}

\subsection{Defining the Complete or "Ideal" Index}

Evaluating the alternative indexes is facilitated by a benchmark to compare the current and proposed procedures. We use for this purpose the current definition of the Leading Index for the U.S. produced by The Conference Board. Let the benchmark index, $I_{t}^{B}$, be the actual value of this index at time $\mathrm{t}$ based on complete data for all components of both the set $X_{t}$ and the set $Y_{t}$. For simplicity, think of $I_{t}^{B}$ as a historical index, which is no longer revised (However, this is not an innocuous assumption, since in practice the recent values of the index are subject to revisions; only after some time (perhaps a year or more) has elapsed can the values of $I_{t}^{B}$ be taken as given).

Because the data for several components of the complete benchmark index are available only with lags, it is impossible to construct $I_{t}^{B}$ in real time for the publication period t. However, apart from any data revisions and assuming complete information can be had with a one-month lag, the current index $I_{t}^{C}$ would equal the ideal index $I_{t}^{B}$ for period $t-1 .{ }^{6}$

Insofar $I_{t}^{C}=I\left(X_{t-1}, Y_{t-1}\right)$, that is, the current index is the benchmark index

lagged one month, $I_{t}^{C}$ is used as a substitute for $I_{t}^{B}$-- essentially, a crude first- 
order autoregressive forecast of $I_{t}^{B}$. In this sense, the current method is itself a simple projection of the (t-1) data to the $\mathrm{t}$-th period.

To serve as a benchmark, our "ideal" index must pass some simple quality tests which are described and presented below. Although standard hypothesis testing plays an important role in testing individual economic theories, it is more difficult to use it for choosing between two or more competing models, as we are doing here. $^{7}$ The use of model selection criteria neatly avoids related sticky issues associated with how to test theories and how to arbitrarily choose significance levels. ${ }^{8}$ Implementing this approach involves a simulated real-time environment (see for example, Diebold and Mariano (1995), and Swanson and White(1997)), thus enabling us to directly assess the relative predictive ability of the leading index.

\subsection{Simple Comparisons with Current and Alternative Indexes}

Chart 1 shows the benchmark index $\mathrm{I}^{\mathrm{B}}$ and the current index $\mathrm{I}^{\mathrm{C}}$ for the period January 1970 - January 2000 (361 monthly observations). The two series

\footnotetext{
${ }^{6}$ As mentioned above, the one-month lag applies to the U.S. index. For other countries, the generally longer and more varied lags make the relationship between $I_{t}^{C}$ and $I_{t}^{B}$ more complicated.

${ }^{7}$ Granger, King and White (1995) suggest that although standard hypothesis testing plays and important role in testing individual economic theories, it is more difficult to justify for choosing between two competing models. One reason for their concern is that one model must be selected as the null, and this model is often the more parsimonious model. However, it is often difficult to distinguish between the two models (because of multicollinearity, near-identification, etc.), so that the null hypothesis may be unfairly favored. ${ }^{8}$ Other commonly used model selection criteria are Akaike Information Criterion and Schwarz Information Criterion, which provide only indirect finite sample evidence concerning the predictive usefulness of a variable (see e.g. Swanson, Ozyildirim and Pisu (2000) for Monte Carlo and related evidence).
} 
are very close but $\mathrm{I}^{\mathrm{B}}$ tends to be above $\mathrm{I}^{\mathrm{C}}$. The differences $\left(\mathrm{I}^{\mathrm{B}}-\mathrm{I}^{\mathrm{C}}\right)$ are plotted separately to a larger scale on the left-hand side. By far most of the time, these discrepancies due to missing data and other measurement errors are positive, generally between zero and two on the index scale (and very similar in percentage terms). This bias is most likely the result of data errors and subsequent revisions, which presumably affect $\mathrm{I}^{\mathrm{C}}$ more strongly and more adversely than they affect $\mathrm{I}^{\mathrm{B}}$. Over time, as the data gaps are filled and the data errors are reduced, the discrepancies between $\mathrm{I}^{\mathrm{B}}$ and $\mathrm{I}^{\mathrm{C}}$ remain largely random and relatively small. Interestingly, their volatility appears to be larger in the first half of the period covered (1970-85) than in the second half (1986-1999). This could reflect the greater stability of real economic activity in the U.S. in the second period.

Chart 2 compares in the same way $\mathrm{I}^{\mathrm{B}}$ and the alternative $\mathrm{AR}(2)$ index $\mathrm{I}^{\mathrm{A}}$. It is important to note that the discrepancies from $\mathrm{I}^{\mathrm{B}}$ are here smaller (generally in the range of -1 to +1 ) and that they are not biased in the sense of being predominantly positive or negative but are approximately symmetrical around the zero line. Again, however, the series of differences $\left(\mathrm{I}^{\mathrm{B}}-\mathrm{I}^{\mathrm{A}}\right)$ shows greater volatility in 1970-85 than in 1986-99.

Both Charts 1 and 2 are based on historical data that have been subject to revisions. Unrevised, real-time data are contaminated by greater measurement errors compared with those in the revised, historical data; hence, the former tend to underperform the latter, particularly when the target of the forecast or analysis 
is itself taken to be in revised ("true") form. Still, it is instructive to see just how much the measurement errors in the unrevised real-time data affect our results. In order to address this issue, we used the unrevised data on the leading indicators from the archives of the Bureau of Economic Analysis in the U.S. Department of Commerce and The Conference Board.

Unfortunately, the resulting sample of real-time data is short, including only 133 monthly observations from January 1989 to January 2000. The period covers one sluggish period around the recession of July 1990- March 1991, including an unusually slow recovery, and one ongoing expansion, including an unusually strong boom with little inflation: so it is rather special as well as short. For the current procedure, the reported values of $\mathrm{I}^{\mathrm{C}}$ are used. For the missing components of the alternative index $\mathrm{I}^{\mathrm{A}}$, each month in the sample is forecast from an $\operatorname{AR}(2)$ equation using data that start in January 1959 and adding one month per each regression. Thus the results are heavily influenced by historical data, especially for the early part of the sample.

Chart 3 shows that most of the time during the $1989-2000$ period $\mathrm{I}^{\mathrm{B}}$ exceeded $\mathrm{I}^{\mathrm{C}}$ so that the discrepancies between the two were positive. $\left(\mathrm{I}^{\mathrm{B}}-\mathrm{I}^{\mathrm{C}}\right)$ had negative values only intermittently in 1989 and more consistently between mid1990 and mid-1991 as well as in the first half of 1995; elsewhere, this series stayed positive, first generally below two percent, later (after mid-1996) mostly between 2 and 4 percent. 
Chart 4 is similar in that here again $\mathrm{I}^{\mathrm{B}}$ shows the highest growth, exceeding $\mathrm{I}^{\mathrm{A}}$ most of the time, and consistently since 1995 ; thus $\left(\mathrm{I}^{\mathrm{B}}-\mathrm{I}^{\mathrm{A}}\right)$ is mostly positive, with some tendency to rise, particularly from mid-1995 to mid-1998. The explanation for both charts is that $\mathrm{I}^{\mathrm{B}}$ is essentially historical, incorporating revisions, whereas $\mathrm{I}^{\mathrm{C}}$ and $\mathrm{I}^{\mathrm{A}}$ have larger "real-time" components with early data vintages. The leading index components with upward trends are shifted upward by cumulative effects of data revisions. In particular, the early data for money supply, new orders for consumer goods and materials, and new orders for nondefense capital goods (all in real terms) underestimate growth relative to the later vintages. Thus what looks like systematic and rising trend differences is here solely the result of measurement errors. ${ }^{9}$

Table 1 collects the summary statistics for the discrepancies between $\mathrm{I}^{\mathrm{B}}$, $\mathrm{I}^{\mathrm{C}}$, and $\mathrm{I}^{\mathrm{A}}$. Here $\mathrm{I}^{\mathrm{A}}$ is represented not only by the $\mathrm{AR}(2)$ model as in our charts (i.e., by $\hat{I}_{t}^{2}$ ) but also by $\mathrm{AR}(1), \operatorname{AR}(3)$, and AR(4) models (i.e., by $\hat{I}_{t}, \hat{I}_{t}^{3}$, and $\hat{I}_{t}^{4}$ respectively). The statistics are mean, standard deviation, and Root Mean Square Errors (RMSE). They show in each case substantial reductions of the discrepancies from $\mathrm{I}^{\mathrm{B}}$ as we move from $\hat{I}_{t}$ to $\hat{I}_{t}$ and $\hat{I}_{t}^{2}$, much smaller (or no)

\footnotetext{
${ }^{9}$ For earlier discussion of similar properties of data errors and revisions, see Zarnowitz (1982) and (1992), chapter 11.
} 
improvements with shifts to $\hat{I}_{t}^{3}$, and $\hat{I}_{t}^{4}$. Thus, for simplicity and uniformity, we choose the AR(2) model as the preferred one.

\section{How Well Does the New Procedure Predict the Coincident Index?}

\subsection{Out-of-Sample Forecasts of Relative Changes in the Coincident Index}

The Leading Index is widely regarded as a tool to forecast changes in the direction of aggregate economic activity and in particular the business cycle turning points. The latter have been historically determined by the reference chronologies of the National Bureau of Economic Research (NBER), but they are well approximated by the dates of peaks and troughs in the Coincident Index. However, as shown by Charts 1 and 2 , the indexes $\mathrm{I}^{\mathrm{B}}, \mathrm{I}^{\mathrm{C}}$, and $\mathrm{I}^{\mathrm{A}}$, have been so close, at least in the last three decades, that they can hardly be distinguished by their timing at the major turning points.

What we do instead here is to take the change in the natural logarithm (ln) of the coincident index $\left(\mathrm{DLC}_{t}\right)$ as the measure of the overall performance of the economy that we are trying to predict month-to-month using the change in the natural logarithm of the leading index $\left(\mathrm{DLI}_{t}\right)$. We regress $\mathrm{DLC}_{t}$ on $\mathrm{DLC}_{\mathrm{t}-1}$ and $\mathrm{DLI}_{\mathrm{t}-\mathrm{i}}$ (where I varies). That is, we ask whether adding the leading index (benchmark, current, or alternative) adds to a simple first-order autoregressive model for $\mathrm{DLC}_{\mathrm{t}}$ by reducing errors of out-of-sample forecasts. In this way, we compare the predictive abilities of the various leading indexes. 
Our approach, then, is to construct a sequence of one-month-ahead forecasts of $\mathrm{DLC}_{\mathrm{t}}$ using first equation (1), a model that estimates

$$
D L C_{t}=\beta_{0}+\beta_{1} D L C_{t-1}+\varepsilon_{t}
$$

Equation (2) augments Equation (1) with lags of DLI, the log change in the leading index:

$$
D L C_{t}=\beta_{0}+\beta_{1} D L C_{t-1}+\beta_{2} D L I_{t-i}^{j}+\varepsilon_{t}
$$

where $\beta_{2}$ is in most cases a distributed lag $(\mathrm{i}=1,2, \ldots)$. The leading index used in (2) is either the benchmark index $\mathrm{I}^{\mathrm{B}}$, the current index, $\mathrm{I}^{\mathrm{C}}$, or the preferred alternative index $\mathrm{I}^{\mathrm{A}}$ based on the second order autoregressive estimates of the missing components.

In Table 2, the historical data sample from January 1970 through January 2000 is used, with the number of monthly observations, $T$, equal to 361 . The first set of regressions covers the data for 1970-73 $(\mathrm{R}=48)$, producing one-monthahead forecasts of $\mathrm{DLC}_{\mathrm{t}}$ for $\mathrm{R}+1$. At this point, we add one more observation, reestimate all coefficients, and form a second one-step-ahead forecast of $\mathrm{DLC}_{\mathrm{t}}$ for $\mathrm{R}+2$. This process continues until the entire sample of $\mathrm{T}$ observations is exhausted, and we are left with $\mathrm{P}=\mathrm{T}-\mathrm{R}$ (313) regression forecasts for each of the four equations used. A sequence of simulated real-time forecast errors is then constructed by subtracting the forecasts from the actual realizations of the 
coincident index. Root mean square errors (RMSE) serve to summarize these numbers.

There are twelve versions of each of the four equations, depending on the different timing combinations used, yielding as many RMSE values in columns 47 of Table 2. This is done in order to accommodate the different ways the leading index is used to make forecasts of the state of the economy and mimic several different rules of thumb applied to movements in this index to derive conclusions on the short term direction of the coincident index. We use 1, 3, 6, and 12 month changes in the natural logs of the leading index as regressors and 1, 3, 6, and 12 month changes in the natural logs of the coincident index as the variable being forecast. In addition, we vary the lag length of the leading index, i, in each model between 1, 3, and 6 lags. The simple autoregressive model of the coincident index always uses one lag of the coincident index. This lag structure along with the way changes in the leading index are constructed should cover a wide variety of ways the leading index is used by analysts and forecasters. While a thorough analysis of the predictive ability of the leading index would account for trending properties of the data and would allow for varying and optimally selected lag lengths of the data, that is not our objective here and is left for future research.

While Table 2 is based on regressions for the historical sample that goes back to 1970, Table 3 applies the same calculations to the short sample of realtime data that begins in 1989. The two tables share the same format: the lags and 
unit periods are identified in columns 2 and 3, the RMSE's in columns 4-7, and the ratios of the RMSE's, in percent, in columns 8-11. Negative ratios indicate that the additions of $\mathrm{DLI}_{\mathrm{t}-\mathrm{i}}$ terms reduce the RMSE's relative to the autoregressions (Eq. 1) or the regressions with the current index (Eq. 3).

A glance at Table 2 shows that the prevalence of minus signs in the last four columns, which is gratifying. All but eight of the 48 entries ( 83 percent) are negative. The same prevalence of improvements is found in columns 8 and 11 of Table 3, which means that the results obtained with the $\mathrm{I}^{\mathrm{B}}$ data are better than the autoregression of $\mathrm{DLC}_{\mathrm{t}}$ and that the new procedure with $\mathrm{I}^{\mathrm{A}}$ works better that the old procedure with $\mathrm{I}^{\mathrm{C}}$. However, the predominantly positive signs in columns 9 and 10 of Table 3 suggest that both $\mathrm{I}^{\mathrm{C}}$ and $\mathrm{I}^{\mathrm{A}}$ fail to contribute to the autoregression of DLC $_{t}$ in this small sample of unrevised data for the 1990.

\subsection{The New Procedure Consistently Outperforms the Current One}

For the full historical sample, which we believe yields more significant results than the short "real-time" sample, our results are clearly supportive of the proposed new procedure. Eq. (4) with $\mathrm{I}^{\mathrm{A}}$ data has lower RMSE's that Eq. (3) with $\mathrm{I}^{\mathrm{C}}$ data in eleven out of the twelve cases covered; also, $\mathrm{I}^{\mathrm{A}}$ produces better results than the autoregressions of $\mathrm{DLC}_{\mathrm{t}}$ in ten out of twelve lines (compare column 7 with columns 6 and 4 in Table 2). Throughout, Eq. (2) with $\mathrm{I}^{\mathrm{B}}$ data ranks first with the lowest RMSE's, Eq. (4) with $\mathrm{I}^{\mathrm{A}}$ data ranks second, and Eq. (3) with $\mathrm{I}^{\mathrm{C}}$ data ranks third in predicting DLC $_{t}$ (however, note that even Eq. (3) tends to work 
better here than the autoregressions of Eq. (1)). The consistency of the results shown by the superscripts in columns 5,6, and 7 is impressive.

Simple averages of the RMSE's in Table 2 are 3.59 for the regression forecasts with the benchmark index $\mathrm{I}^{\mathrm{B}}, 3.76$ for those with the new alternative index $\mathrm{I}^{\mathrm{A}}, 3.86$ for those with the current index $\mathrm{I}^{\mathrm{C}}$, and 4.09 for the autoregressive forecasts (referring to means of columns 5,7,6, and 4 respectively).

In Table 3, too, Eq. (2) forecasts rank first in terms of lowest RMSE's, Eq. (4) forecasts rank second, and Eq. (3) forecasts rank third (see superscripts in columns 5,6, and 7). That is, again, the hypothetical $\mathrm{I}^{\mathrm{B}}$ is best and $\mathrm{I}^{\mathrm{A}}$ approximates it more closely than $\mathrm{I}^{\mathrm{C}}$. The differences between the RMSE's, however, here and in Table 2, are often small.

Whereas for the longer historical sample the autoregressions are inferior, for the short real-time sample they yield on average smaller RMSE's than both the $\mathrm{I}^{\mathrm{C}}$ and the $\mathrm{I}^{\mathrm{A}}$ equations. The mean RMSE's in Table 3 are 2.55 for the regression forecasts with $\mathrm{I}^{\mathrm{B}}$ data, 2.64 for the autoregressive forecasts, 2.75 for those with $\mathrm{I}^{\mathrm{A}}$ data, and 2.89 for those with $\mathrm{I}^{\mathrm{C}}$.

\section{Concluding Thoughts}

In this paper we propose a new composite index procedure which could go a long way towards improving the ex-ante forecasting performance of the leading index. Our procedure combines current financial information with forecasts or 
estimates of real variables that are only available with a lag. It is a superior alternative to using the 50 percent or similar rules described in the introduction. The proposed index is constructed with a complete set of components using actual and forecasted data. This approach to constructing the leading index uses available information more efficiently than the current method and appears to have significant advantages over it. Because of such consistent, even though often small, improvements, the proposed approach should be adopted by The Conference Board.

Empirical evidence points to stock prices and/or interest rate spreads as good leading indicators and predictors of business cycle turning points (see, for example Stock and Watson (1989, 1999), Estrella and Mishkin (1998) and Chauvet (1999). Although the selected financial series are useful as leading indicators, the composite leading index should be better because it includes, in addition to these series, other measures of real economic activity, and hence is more comprehensive. ${ }^{10}$ Then, why is there evidence to the contrary in ex-ante analyses? Part of the reason could be that, as currently calculated, the leading index is not as up-to-date as the financial indicators. Thus, Chauvet (1999) proposes an index based on financial indicators that only includes data available in real time and finds that index to have considerable advantages. In contrast, the current procedure for calculating the leading index leaves out the most recent data 
for financial indicators. This may be responsible for the poor performance of the current leading index found in several recent studies. The proposed alternative index should prove superior.

${ }^{10}$ Comparison of the performance of real versus financial indicators indicates that the quality of their performance in anticipating recessions varies across business cycles. 


\section{References}

Chauvet, M. (1999), "Stock Market Fluctuations and The Business Cycle," Working Paper, University of California, Riverside.

The Conference Board (2001), Business Cycle Indicators

Handbook, New York, NY, forthcoming.

Diebold, F.X. and R.S. Mariano (1995), “Comparing Predictive Accuracy," Journal of Business and Economic Statistics, 13, 253-263.

Estrella, A. and F.S. Mishkin (1998), "Predicting U.S. Recessions:

Financial Variables as Leading Indicators," The Review of Economics and Statistics, 80, 45-61.

Granger, C.W.J., King, M.L. and White, H. (1995), “Comments on Testing Economic Theories and the Use of Model Selection Criteria," Journal of Econometrics, 67, 173-187.

Stock, J. H. and M.W. Watson (1989), "New Indexes of Coincident and Leading Economic Indicators," in NBER Macroeconomics Annual 1989, eds. O. Blanchard and S. Fischer, Cambridge, MA: MIT Press.

Stock, J. H. and M.W. Watson (1999), "Business Cycle Fluctuations in U.S. Macroeconomic Time Series," in Handbook of 
Macroeconomics, eds. J. Taylor and M. Woodford, 1A, Amsterdam: North Holland.

Swanson, N.R. and H. White (1997), "Forecasting Economic Time Series Using Adaptive versus Nonadaptive and Linear versus Nonlinear Econometric Models," International Journal of Forecasting, 13, 439-461.

Swanson, N.R. A. Ozyildirim and M. Pisu (2000), “A Comparison of Alternative Causality and Predictive Ability Tests in the Presence of Integrated and Cointegrated Economic Variables," forthcoming in Computer Aided Econometrics, ed. David Giles, 2001, New York: Marcel Dekker.

Zarnowitz, Victor (1982), “On Functions, Quality, and Timeliness of Economic Information," Journal of Business, 55, 87-119. (1992), Business Cycles: Theory, History, Indicators, and Forecasting, Chicago, Illinois: the University of Chicago Press, pp. 316-356. 
Table 1: Discrepancies Between the Benchmark Leading Index, $I_{t}^{B}$, and Leading

Indexes, $I_{t}^{C}, I_{t}^{1}-I_{t}^{4}$

\begin{tabular}{|c|c|c|c|c|c|c|}
\hline \multirow[t]{2}{*}{$\begin{array}{l}\text { Measurement } \\
\text { Error }^{\mathrm{a}}\end{array}$} & \multicolumn{3}{|c|}{ Jan. 1970-Jan. 2000 } & \multicolumn{3}{|c|}{ Jan. 1989-Jan. 2000 } \\
\hline & Mean & $\begin{array}{l}\text { Standard } \\
\text { Deviation }\end{array}$ & RMSE & Mean & $\begin{array}{l}\text { Standard } \\
\text { Deviation }\end{array}$ & RMSE $^{\text {d }}$ \\
\hline$I_{t}^{B}-I_{t}^{C}$ & 1.514 & 1.203 & 1.011 & 2.366 & 1.605 & 1.706 \\
\hline$I_{t}^{B}-\hat{I}_{t}$ & 0.777 & 1.088 & 0.646 & 2.268 & 1.640 & 1.620 \\
\hline$I_{t}^{B}-\hat{I}_{t}^{2}$ & 0.760 & 1.034 & 0.592 & 2.234 & 1.581 & 1.572 \\
\hline$I_{t}^{B}-\hat{I}_{t}^{3}$ & 0.752 & 1.029 & 0.591 & 2.227 & 1.576 & 1.567 \\
\hline$I_{t}^{B}-\hat{I}_{t}^{4}$ & 0.753 & 1.029 & 0.592 & 2.224 & 1.575 & 1.565 \\
\hline
\end{tabular}

${ }^{a} I_{t}$ is the index calculated using the current methodology for the US Leading Index. Alternative indexes $I_{t}^{j}$ have been calculated using estimates for the data which would be missing in the publication period and actual values for the data which would be available in the publication period (stock prices and the interest rate spread). The estimates of the missing data in alternative indexes $I_{t}^{j}$, where $\mathrm{j}=1,2,3,4$, have been derived using autoregressive models of order $\mathrm{j}$.

${ }^{\mathrm{b}}$ Jan. 1970-Jan. 2000 is the sample of historical data that was used in the analysis. The measurement error $\left(I_{t}^{B}-I_{t}^{j}\right)$, where $\mathrm{j}=\mathrm{C}, 1,2,3,4$, were calculated over the sample of 361 monthly observations.

${ }^{c}$ Jan. 1989-Jan. 2000 is the short sample of unrevised real-time data that was used in the analysis. The measurement errors $\left(I_{t}^{B}-I_{t}^{j}\right)$, where $\mathrm{j}=\mathrm{C}, 1,2,3,4$, were calculated over the sample of 133 monthly observations.

d $R M S E=\sqrt{\frac{\sum e^{2}}{n}}$ where e is equal to $\left(I_{t}^{B}-I_{t}^{j}\right)$, where $\mathrm{j}=\mathrm{C}, 1,2,3,4$, and $\mathrm{n}=361$ in the Jan. 1970-Jan. 2000 sample and $n=133$ in the Jan. 1989-Jan. 2000 sample. 
Table 2: Predicting Log Changes in the US Coincident Index, Monthly, 1970-2000:

Autoregression and Contributions of Log Changes in the US Leading Index ${ }^{a}$

\begin{tabular}{|c|c|c|c|c|c|c|c|c|c|c|}
\hline \multirow[t]{3}{*}{ Line } & \multirow[t]{3}{*}{$\begin{array}{l}\text { Lags of Leading } \\
\text { Index (in } \\
\text { months) }\end{array}$} & \multirow[t]{3}{*}{$\begin{array}{l}\text { Unit Period } \\
\text { (months of } \\
\text { changes) }^{c}\end{array}$} & \multicolumn{4}{|c|}{$\begin{array}{l}\text { Root Mean Square Errors } \\
\text { (RMSE) }^{\text {d }}\end{array}$} & \multicolumn{4}{|c|}{ Percent Ratios of the RMSE' $s$} \\
\hline & & & \multirow{2}{*}{ Eq.(1) } & \multirow{2}{*}{ Eq.(2) } & \multirow{2}{*}{ Eq.(3) } & \multirow{2}{*}{ Eq.(4) } & $E q \cdot(2)$ & $E q .(3)$ & $E q .(4)$ & $E q .(4)$ \\
\hline & & & & & & & $\overline{E q .(1)}$ & $\overline{E q .(1)}$ & $\overline{E q .(1)}$ & $E q .(3)$ \\
\hline (1) & (2) & (3) & (4) & (5) & (6) & (7) & (8) & (9) & (10) & (11) \\
\hline 1 & 1 & 1 & 3.11 & $2.94^{1}$ & $3.04^{3}$ & $3.04^{2}$ & -5.59 & -2.14 & -2.30 & -0.16 \\
\hline 2 & 1 & 3 & 3.83 & $3.61^{1}$ & $3.85^{3}$ & $3.82^{2}$ & -5.96 & 0.34 & -0.34 & -0.68 \\
\hline 3 & 1 & 6 & 4.53 & $3.96^{1}$ & $4.28^{3}$ & $4.14^{2}$ & -12.49 & -5.52 & -8.67 & -3.33 \\
\hline 4 & 1 & 12 & 4.88 & $3.99^{1}$ & $4.29^{3}$ & $4.10^{2}$ & -18.26 & -12.07 & -15.98 & -4.45 \\
\hline 5 & 3 & 1 & 3.11 & $2.90^{1}$ & $3.02^{3}$ & $3.02^{2}$ & -6.74 & -2.89 & -2.89 & 0.00 \\
\hline 6 & 3 & 3 & 3.83 & $3.55^{1}$ & $3.89^{2}$ & $3.90^{3}$ & -7.42 & 1.35 & 1.69 & 0.33 \\
\hline 7 & 3 & 6 & 4.53 & $3.89^{1}$ & $4.15^{3}$ & $4.01^{2}$ & -14.18 & -8.40 & -11.38 & -3.25 \\
\hline 8 & 3 & 12 & 4.88 & $3.82^{1}$ & $4.17^{3}$ & $3.94^{2}$ & -21.68 & -14.50 & -19.30 & -5.62 \\
\hline 9 & 6 & 1 & 3.11 & $2.96^{1}$ & $3.04^{3}$ & $3.02^{2}$ & -4.93 & -2.25 & -2.73 & -0.49 \\
\hline 10 & 6 & 3 & 3.83 & $3.65^{1}$ & $3.99^{3}$ & $3.99^{2}$ & -4.88 & 4.00 & 4.00 & 0.00 \\
\hline 11 & 6 & 6 & 4.53 & $3.91^{1}$ & $4.29^{3}$ & $4.12^{2}$ & -13.61 & -5.26 & -8.94 & -3.88 \\
\hline 12 & 6 & 12 & 4.88 & $3.92^{1}$ & $4.34^{3}$ & $4.07^{2}$ & -19.56 & -11.12 & -16.48 & -6.03 \\
\hline
\end{tabular}

${ }^{a}$ Let DLC(DLI) denote the monthly change in the natural logarithm of the US Coincident Index (Leading Index). The equation (1) regresses $D L C_{t}$ on $D L C_{t-1}$. Eq. (2) regresses $D L C_{t}$ on $D L C_{t-1}$ and $D L I_{t-i}^{B}$, where $I_{t}^{B}$ is the benchmark leading index. Eq. (3) regresses $D L C_{t}$ on $D L C_{t-1}$ and $D L I_{t-i}^{C}$, where $I_{t}^{C}$ is the current leading index. Eq. (4) regresses $D L C_{t}$ on $D L C_{t-1}$ and $D L I_{t-i}^{A}$, where $I_{t}^{A}$ is the new selected alternative leading index based on $\mathrm{AR}(2)$ component forecasts.

${ }^{\mathrm{b}}$ Refers to "i" in the time subscript of the leading index (as in $D L I_{t-i}^{B}, \mathrm{i}=1,3,6$; see note a above).

${ }^{\mathrm{c}}$ Refers to the span of changes, in months, over which the differences in $C_{t}$ and $I_{t}$ are calculated. For example, in lines 2,6, and 10 three-month changes are used in equations (1) to (4); in lines 4, 8, and 12 twelve-month changes are used in the same equations.

${ }^{\mathrm{d}} R M S E=\sqrt{\frac{\sum e^{2}}{n}}$, where $\mathrm{e}$ is the one-step-ahead forecast error and $\mathrm{n}$ is the number of simulated real-time forecasts made. In each of the four equations, the RMSE's summarize 313 regressions based on the sample of 361 monthly observations for Jan. 1970 - Jan. 2000. The first regression was run on data for the first 48 months of the sample and each of the successive regressions added one more month. Each of the RMSE's reported in columns 4-7 sums up the errors of the one-month-ahead-forecasts from each of the 313 regressions. The RMSE's for equations (2), (3), and (4) are ranked 1,2, and 3 for best (lowest), intermediate, and worst (highest), respectively. The ranks are identified by superscripts. Entries are RMSE* $10^{6}$.

${ }^{\mathrm{e}}$ Here (1), (2), (3), and (4) stand for the RMSE's for equations (1), (2), (3), and (4) respectively. The percent ratio equals $[(E q .(2) / E q .(1))-1] * 100$. Negative ratios indicate reductions of RMSE relative to Eq. (1) in columns 8, 9, and 10 and relative to Eq. (3) in column 11. 
Table 3: Predicting Log Changes in the US Coincident Index, Monthly, 1989-2000:

Autoregression and Contributions of Log Changes in the US Leading Index ${ }^{\text {a }}$

\begin{tabular}{|c|c|c|c|c|c|c|c|c|c|c|}
\hline \multirow[t]{3}{*}{ Line } & \multirow[t]{3}{*}{$\begin{array}{l}\text { Lags of Leading } \\
\text { Index (in } \\
\text { months) }\end{array}$} & \multirow[t]{3}{*}{$\begin{array}{l}\text { Unit Period } \\
\text { (months of } \\
\text { changes) }\end{array}$} & \multicolumn{4}{|c|}{$\begin{array}{l}\text { Root Mean Square Errors } \\
\text { (RMSE) }^{\text {d }}\end{array}$} & \multicolumn{4}{|c|}{ Percent Ratios of the RMSE's $\mathrm{e}$} \\
\hline & & & \multirow{2}{*}{ Eq.(1) } & \multirow{2}{*}{ Eq.(2) } & \multirow{2}{*}{ Eq.(3) } & \multirow{2}{*}{ Eq.(4) } & $E q .(2)$ & $E q .(3)$ & $E q .(4)$ & $E q \cdot(4)$ \\
\hline & & & & & & & $E q .(1)$ & $\overline{E q .(1)}$ & $E q .(1)$ & Eq.(3) \\
\hline (1) & (2) & (3) & (4) & (5) & (6) & (7) & (8) & (9) & (10) & (11) \\
\hline 1 & 1 & 1 & 2.08 & $2.02^{1}$ & $2.09^{2}$ & $2.10^{3}$ & -2.92 & 0.46 & 0.69 & 0.23 \\
\hline 2 & 1 & 3 & 2.30 & $2.31^{2}$ & $2.29^{1}$ & $2.34^{3}$ & 0.28 & -0.28 & 1.69 & 1.98 \\
\hline 3 & 1 & 6 & 2.66 & $2.58^{1}$ & $2.77^{3}$ & $2.71^{2}$ & -3.00 & 3.87 & 1.61 & -2.18 \\
\hline 4 & 1 & 12 & 3.00 & $2.82^{1}$ & $3.22^{3}$ & $3.09^{2}$ & -5.84 & 7.50 & 2.90 & -4.27 \\
\hline 5 & 3 & 1 & 2.54 & $2.35^{1}$ & $2.68^{3}$ & $2.49^{2}$ & -7.42 & 5.52 & -1.80 & -6.94 \\
\hline 6 & 3 & 3 & 3.06 & $2.92^{1}$ & $3.44^{3}$ & $3.27^{2}$ & -4.65 & 12.34 & 6.98 & -4.78 \\
\hline 7 & 3 & 6 & 2.66 & $2.66^{1}$ & $3.05^{3}$ & $2.84^{2}$ & -0.28 & 14.57 & 6.74 & -6.83 \\
\hline 8 & 3 & 12 & 2.53 & $2.43^{1}$ & $2.68^{3}$ & $2.57^{2}$ & -4.05 & 5.68 & 1.55 & -3.91 \\
\hline 9 & 6 & 1 & 2.54 & $2.36^{1}$ & $2.76^{3}$ & $2.52^{2}$ & -7.08 & 8.92 & -0.86 & -8.98 \\
\hline 10 & 6 & 3 & 2.53 & $2.46^{1}$ & $2.74^{3}$ & $2.65^{2}$ & -3.08 & 8.16 & 4.49 & -3.39 \\
\hline 11 & 6 & 6 & 2.66 & $2.62^{1}$ & $3.19^{3}$ & $2.97^{2}$ & -1.49 & 19.86 & 11.58 & -6.91 \\
\hline 12 & 6 & 12 & 3.06 & $3.06^{1}$ & $3.75^{3}$ & $3.45^{2}$ & 0.11 & 22.80 & 12.82 & -8.13 \\
\hline
\end{tabular}

a,b,c,e See Table notes a, b, c, and e respectively.

${ }^{\mathrm{d}}$ See Table 2 note $\mathrm{d}$. In addition, in each of the four equations, the RMSE's summarize 97 regressions based on the sample of 133 monthly observations for Jan. 1989 - Jan. 2000. The first regression was run on data for the first 36 months of the sample and each of the successive regressions added one more month. Each of the RMSE's reported in columns 4-7 sums up the errors of the one-month-ahead-forecasts from each of the 97 regressions. 


\section{APPENDIX 1}

Table A1:Components of the U.S. Index of Leading Indicators ${ }^{11}$

Leading Indicator:

Lag in Data

Average weekly hours Availability

Average initial claims $-1$

New orders, consumer goods

$-1$

Vendor performance

$-1$

New orders, capital goods

Building permits

Stock prices

$-1$

Money supply

Interest rate spread

$-1$

Consumer expectations

${ }^{11}$ A lag of 0 indicates that the series is available in the publication period. A lag of -1 indicates that publication lag is one month. Then, the forecast for the series used in the construction of an alternative index is a 1-step ahead forecast. 


\section{Chart 1}

U.S. Leading Indexes, 1970-2000: Benchmark vs. Current and Discrepancies $I^{B}-I^{C}$

(IB-IC) - . - IB IB IC

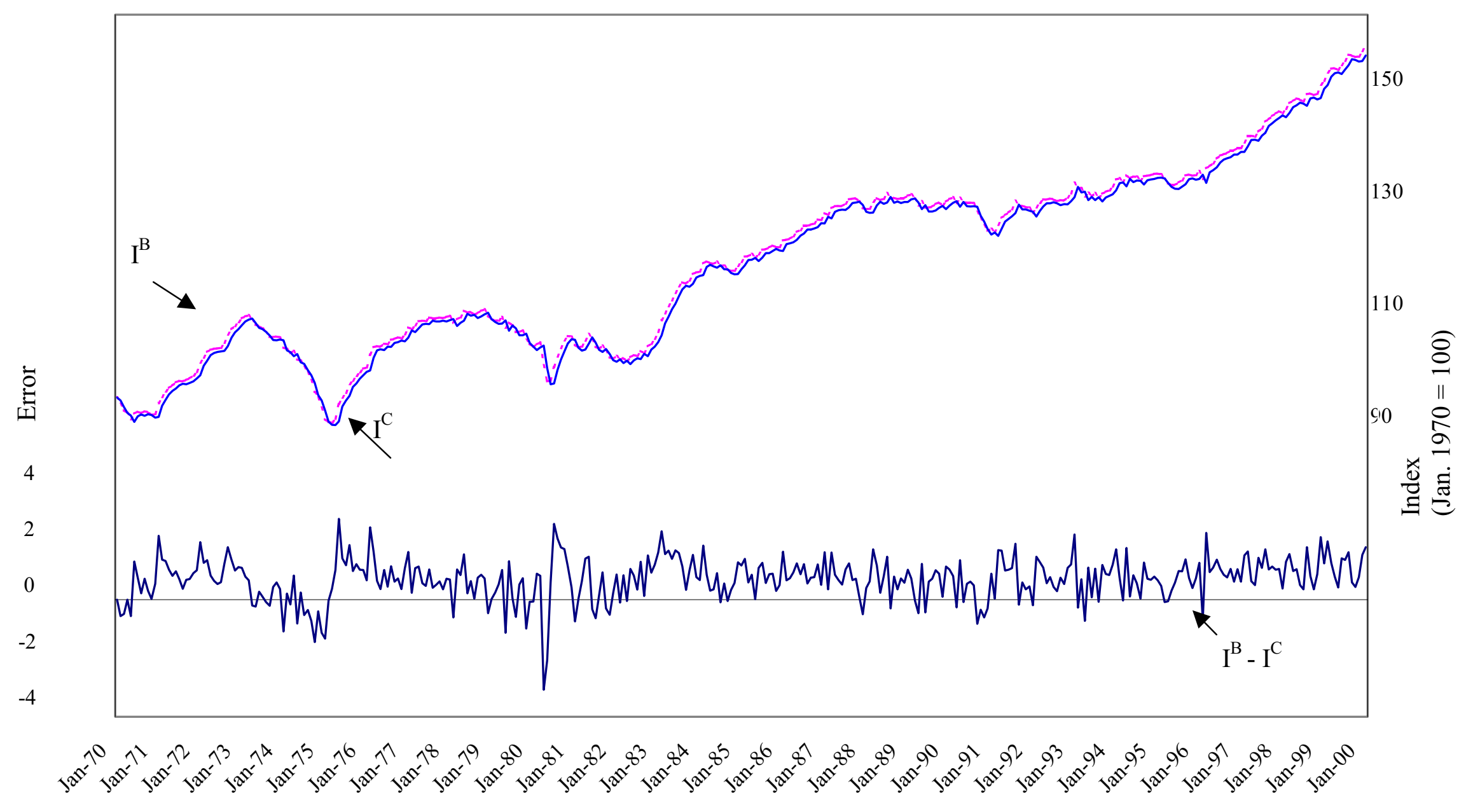




\section{Chart 2}

U.S. Leading Indexes, 1970-2000: Benchmark vs. Alternative and Discrepancies $I^{B}-I^{A}$

- (IB-IA) - .... IB - IA

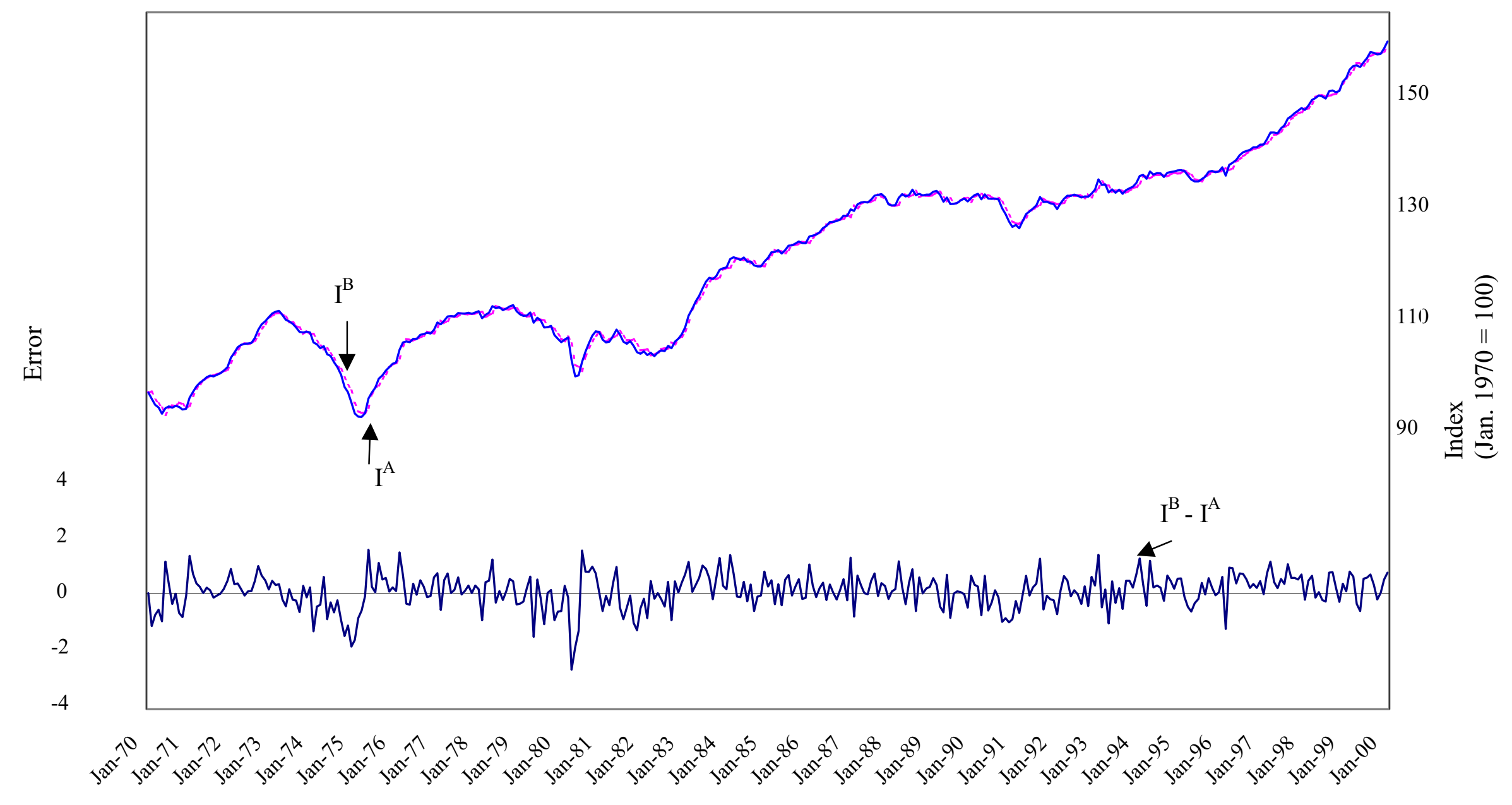




\section{Chart 3}

U.S. Leading Indexes, 1989-2000: Benchmark vs. Current and Discrepancies $I^{\mathrm{B}}-\mathrm{I}^{\mathrm{C}}$

$\longrightarrow(\mathrm{IB}-\mathrm{IC}) \cdots \cdot-\cdots$ IB $-\mathrm{IC}$

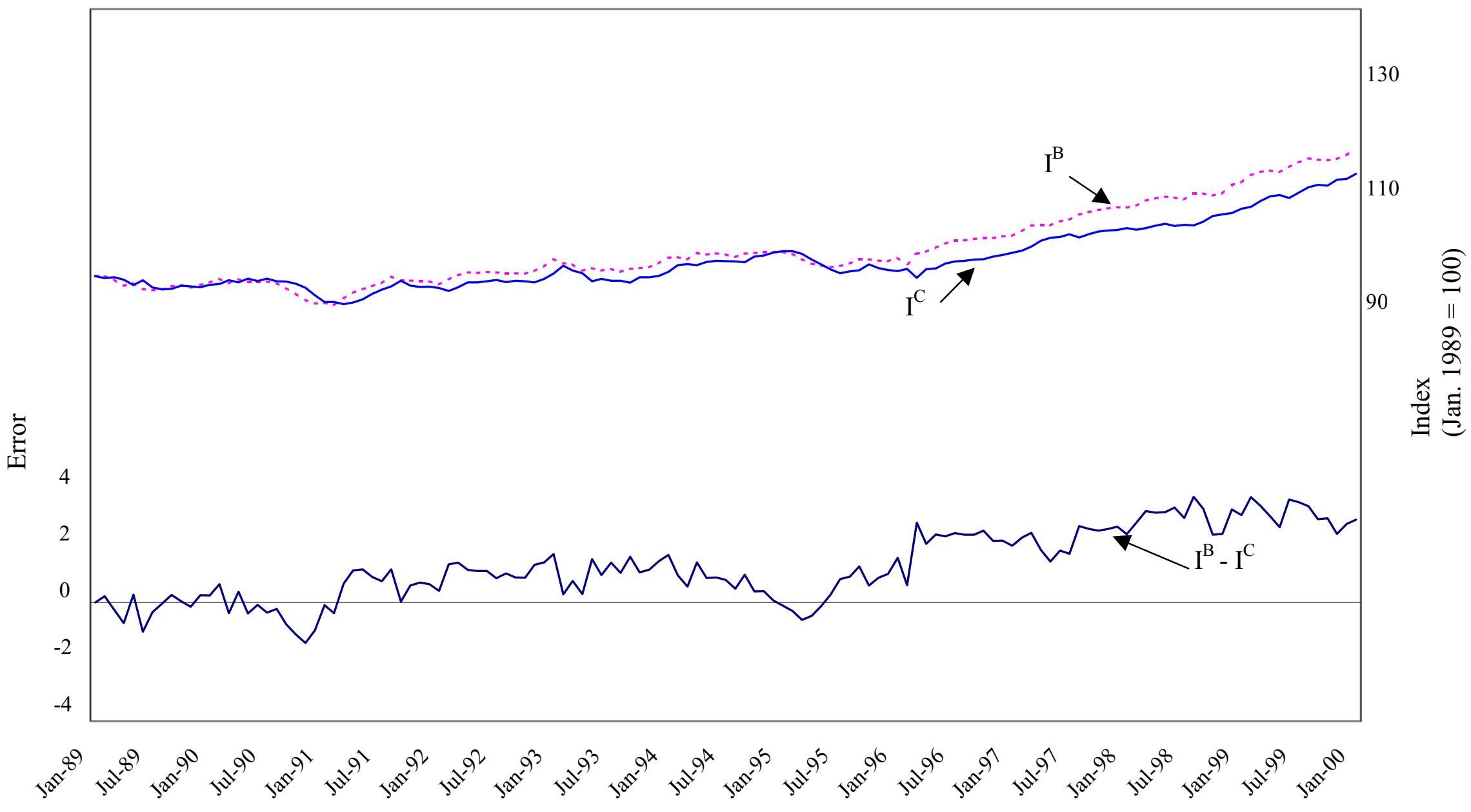




\section{Chart 4}

U.S. Leading Indexes, 1989-2000: Benchmark vs. Alternative and Discrepancies $I^{B}$ - $I^{A}$

- (IB-IA) - - - - IB IB IA

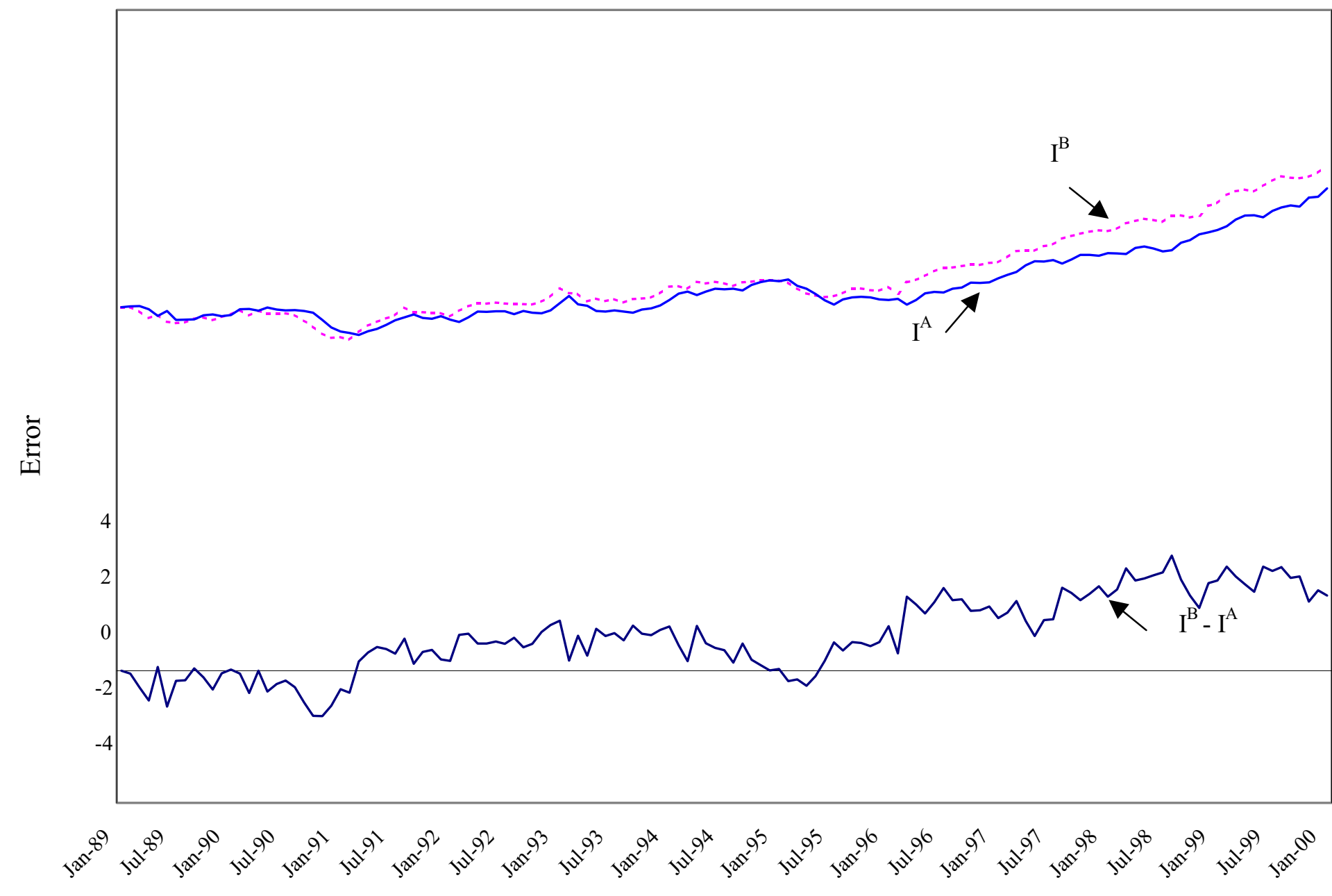

